\title{
Large Vessel Vasculitis in a Patient with Systemic Lupus Erythematosus Presenting as Takayasu's Pulseless Arteritis
}

\author{
Cathy-Lee Jagdeo, Stephanie Battersby, Azad Esack \\ Department of Neurology, The Eric Williams Medical Sciences Complex, Mt. Hope, Trinidad and Tobago \\ Email: neuroservices@gmail.com
}

How to cite this paper: Jagdeo, C.-L., Battersby, S. and Esack, A. (2021) Large Vessel Vasculitis in a Patient with Systemic Lupus Erythematosus Presenting as Takayasu's Pulseless Arteritis. International Journal of Clinical Medicine, 12, 415-423.

https://doi.org/10.4236/ijcm.2021.1210037

Received: March 21, 2021

Accepted: October 8, 2021

Published: October 11, 2021

Copyright $\odot 2021$ by author(s) and Scientific Research Publishing Inc. This work is licensed under the Creative Commons Attribution International License (CC BY 4.0).

http://creativecommons.org/licenses/by/4.0/

\begin{abstract}
Systemic lupus erythematosus (SLE) with an associated aortoarteritis presenting as an ischemic stroke is a rarity in the medical literature. We report the case of an 11-year-old male presenting with an acute ischemic stroke meeting the criteria for the diagnosis of SLE and findings consistent with an aortitis on imaging but mimicking the diagnosis of Takayasu's pulseless arteritis. Blood and imaging investigations revealed the finding of SLE aortitis following an acute stroke presentation. Thus, it is imperative to note that even though it is infrequent, SLE can be associated with a large vessel vasculitis.
\end{abstract}

\section{Keywords}

Systemic Lupus Erythematosus, Aortoarteritis, Takayasu's

Pulseless Arteritis

\section{Introduction}

It is well recognized that the two common causes of large vessel arteritis are giant cell arteritis and Takayasu's pulseless arteritis [1]. A less well known, cause is SLE especially SLE affecting the aorta and the great vessels arising from the aorta [2]. It is not uncommon for an ischaemic stroke to be caused by SLE but the pathophysiology usually involves vasculitis affecting smaller vessels and or increased stickiness of the blood itself [3].

There is a myriad of etiologies for stroke presentation in the younger population. Strokes in the pediatric groups of patients are relatively rare in which the reported incidence of strokes (ischemic and hemorrhagic) in children under 18 years old was reported to be 1.2 to 13 cases per 100,000 patients [4].

Etiologies of strokes range from cardio embolic phenomena, atherosclerosis 
and inflammatory diseases [5]. Vasculitis can lead to aneurysm formation or stenoses of the affected blood vessels which can result in limitation of blood flow to the brain resulting in stroke [6].

In this case report, the patient presented with an acute ischemic stroke in which the etiology was revealed as a lupus arteritis presentation with an associated large vessel vasculitis (aortitis); a rare occurrence as noted throughout the medical literature.

\section{Case Report}

This is the clinical case report of an 11 year old Afro-Caribbean boy who presented with sudden onset of left upper limb and left lower limb weakness over a period of 2 days. The patient had a background history of a normocytic anaemia which was previously being investigated. Prior to this, there was one hospital admission 2 years ago when the patient presented with arthralgia and chest pain for which no definitive diagnosis was made at the time.

There were also complaints of facial twisting, slurred speech, intermittent diplopia and generalized headaches associated with two isolated episodes of fever.

On physical examination on admission, the boy was noted to have a BP 114/66 $\mathrm{mmHg}$, a tachycardia of 117 beats per minute and he was tachypneic with a temperature of 37.9 degrees Celsius. His oxygen saturation on room air was $97 \%$ and his random blood glucose was recorded as $113 \mathrm{mg} / \mathrm{dL}$. There was a grade $2 / 6$ ejection systolic murmur noted in the aortic region with no radiation. Auscultation of the chest and abdominal examination were both unremarkable.

On neurological examination, his Glasgow coma scale score was 15/15 and the patient was oriented to time, person and place. Visual field testing revealed a left incongruous homonymous hemianopia. Fundoscopy was normal. A left upper motor facial weakness was present. Bulbar function and speech were normal.

On limb examination, tone was markedly reduced in the left upper and lower limbs. The power of the left upper and lower limb was 0/5, whilst the power of the right upper and lower limb was 5/5. The patient was hyperreflexic throughout with left ankle clonus and a left up going plantar response. There were no abnormal cerebellar or sensory findings and the gait could not be assessed.

Both radial and the right posterior tibial pulses were palpably absent.

\section{Results}

CT brain without contrast revealed wedge shaped hypo densities in the right superior fronto-parietal region as shown below in Figure 1.

On contrast administration, there was no enhancement of the lesions.

MRI/Angiogram brain demonstrated a large right cerebral infarct involving the right middle cerebral artery territory mainly, plus an absent right internal carotid artery and attenuation of the right middle cerebral artery (Figure 2 and Figure 3). 


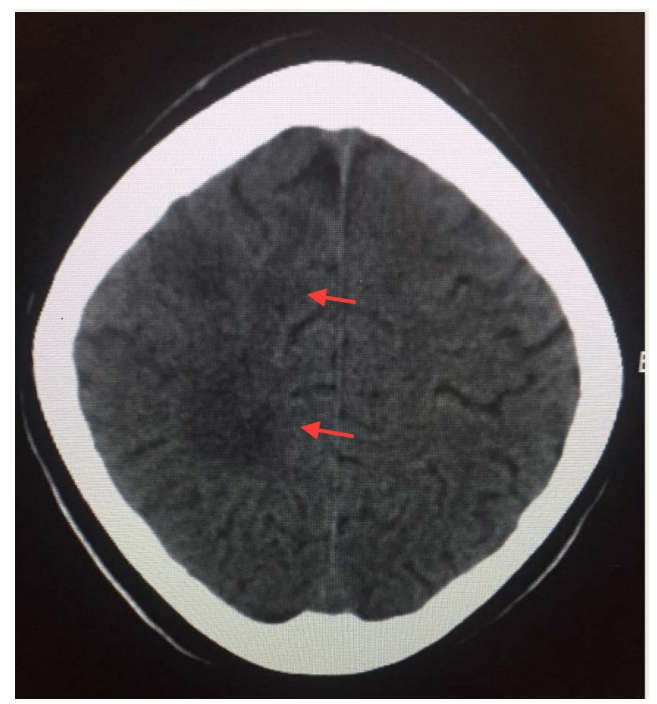

Figure 1. CT brain non contrast demonstrating hypo densities in right superior fronto-parietal region.

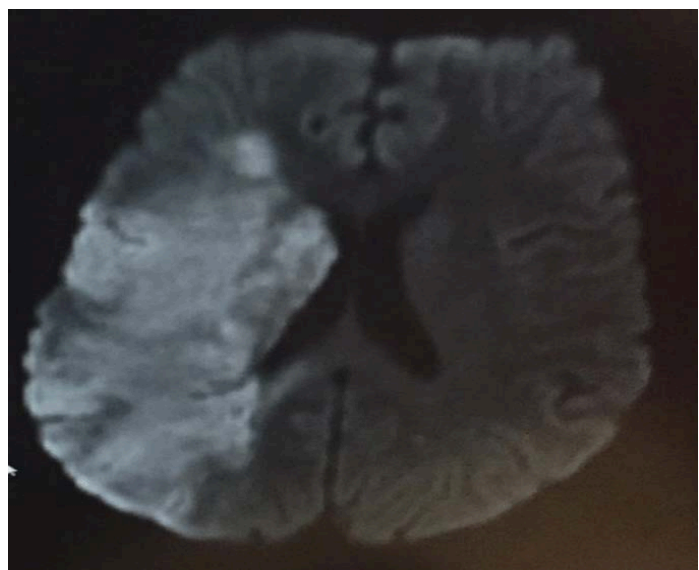

Figure 2. MRI Brain Scan showing large right cerebral infarct.

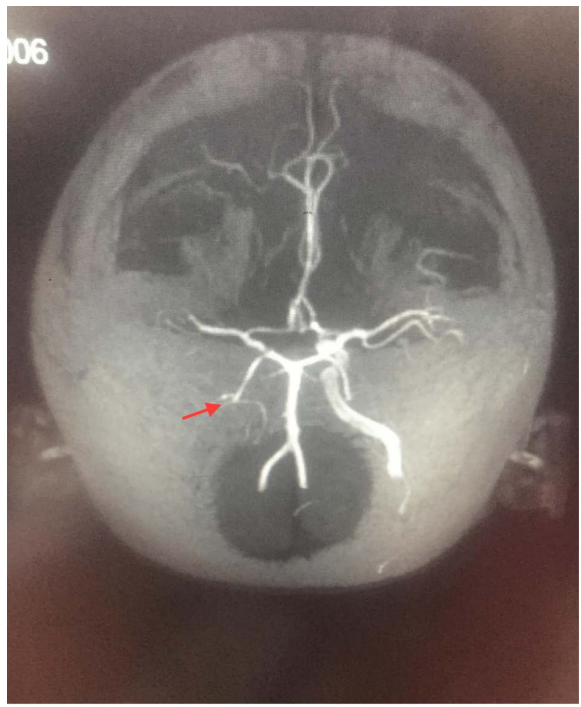

Figure 3. absent right internal carotid and attenuation of the right middle cerebral artery. 
CT angiogram showed a filling defect in the proximal right common carotid and abnormalities in the aortic arch consistent with inflammatory disease (Figure 4 and Figure 5).

A normocytic normochromic anaemia was noted with a $\mathrm{Hb} 8.6 \mathrm{~g} / \mathrm{dL}$. There was no renal impairment with a $\mathrm{Cr} 1.0$ and electrolytes all within normal limits. Liver function tests were within normal limits while the erythrocyte sedimentation rate (ESR) was $>125 \mathrm{mmhr}^{-1}$ and C-reactive protein was elevated $242 \mathrm{mg} / \mathrm{dL}$.

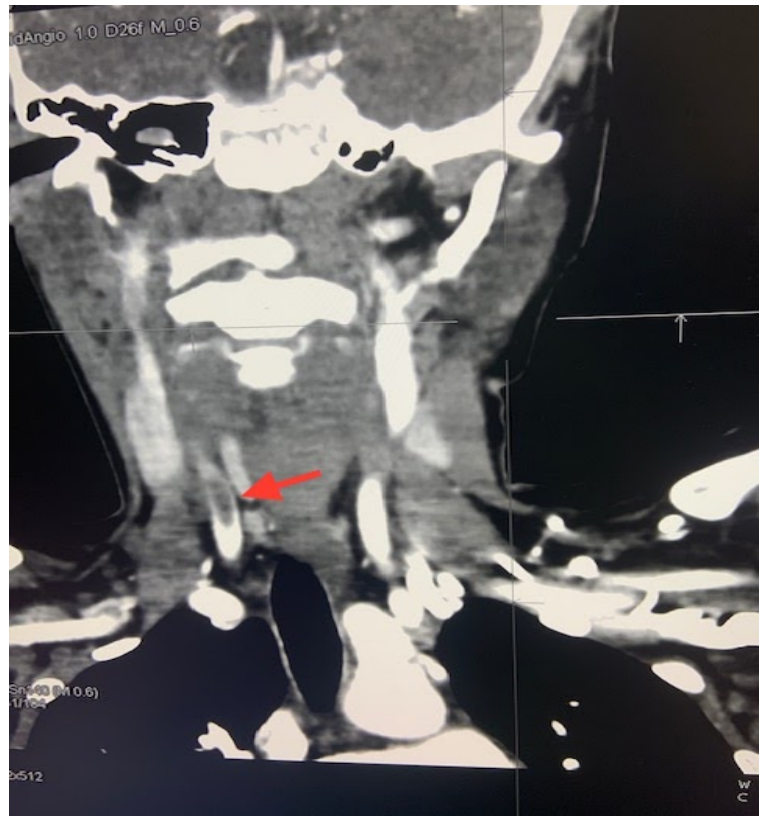

Figure 4. CT carotids showing a central filling defect in the proximal aspect of the right common carotid artery.

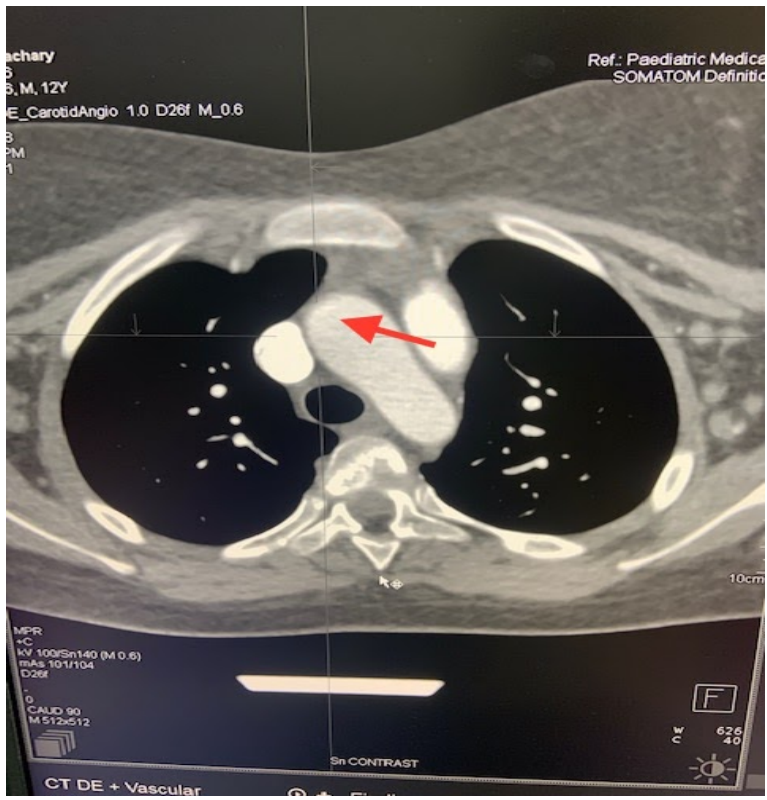

Figure 5. CT chest angiogram demonstrating hypo densities seen in intimal wall of the aortic arch. 
Fasting lipid profiles were as follows Total Cholesterol $146 \mathrm{mg} / \mathrm{dL}$, TG 119 $\mathrm{mg} / \mathrm{dL}$, HDL $21 \mathrm{mg} / \mathrm{dL}$, LDL $102 \mathrm{mg} / \mathrm{dL}$ and VLDL $24 \mathrm{mg} / \mathrm{dL}$. Coagulation studies and thyroid function were within normal limits. Other significant investigations were as follows as shown in Table 1.

ECG showed normal sinus rhythm and transthoracic echocardiogram done on 2 separate occasions demonstrated a normal left ventricle and valves without any evidence of thrombus, vegetation or shunts.

\section{Management}

Before the results of the autoimmune screen (ANA, dsDNA) were available, the initial thought was a diagnosis of Takayasu's pulseless arteritis.

The patient was treated with methylprednisolone $1 \mathrm{~g}$ iv od for 3 days followed by high dose prednisolone on alternating days. He became drowsy whilst his ESR remained $>125 \mathrm{mmHr}^{-1}$ following steroid administration.

Table 1. Blood investigations.

\begin{tabular}{|c|c|}
\hline HIV Rapid Test & Negative \\
\hline $\mathrm{Hb}$ Electrophoresis & $\mathrm{A} 1+\mathrm{A} 2$ \\
\hline Sickle Cell Test & Negative \\
\hline Urine Cocaine & Negative \\
\hline Urine Marijuana & Negative \\
\hline VDRL & Non reactive \\
\hline $\mathrm{Hb} \mathrm{Alc}$ & $4.6 \%$ \\
\hline HepBsAg & Negative \\
\hline Anti-HCV & Negative \\
\hline Rheumatoid Factor & Negative \\
\hline Blood culture $\times 4$ & NBG \\
\hline Urine Culture & NBG \\
\hline Urinalysis & NAD \\
\hline ANA & Positive \\
\hline Anti-dsDNA & 67.19 (Positive) \\
\hline ANF & 126.85 (Positive) \\
\hline Homocysteine & 6.3 (normal) \\
\hline pANCA & 32.76 (elevated) \\
\hline cANCA & 63.83 (elevated) \\
\hline Anti-thrombin & Not done \\
\hline Protein C & 122 (normal) \\
\hline Protein S & 6.9 (low) \\
\hline Factor V leiden & 2.21 (normal) \\
\hline Anti-cardiolipin antibodies & negative \\
\hline
\end{tabular}


Prednisolone was then switched to dexamethasone $4 \mathrm{mg}$ iv tid. However, the boy looked distinctly unwell and his ESR still remained persistently elevated above $125 \mathrm{mmHr}^{-1}$.

There was a new complaint of visual blurring of the right eye. Fundoscopic examination revealed a pale retina and possibly early optic atrophy of the right eye (Figure 6).

Intravenous immunoglobulin (IVIG) $(0.4 \mathrm{~g} / \mathrm{kg} /$ day) was then administered for 5 days.

After a small number of days there was slow but steady improvement in the patient's overall condition. Daily physiotherapy and stroke rehabilitation were instituted after which the patient was discharged on oral prednisolone and followed in the outpatient clinic.

Two weeks later the boy appeared better. His peripheral pulses returned and the ESR started to trend downward. One month later, he was walking with help but left arm function was still very much impaired. He remains on a reducing dose of oral prednisolone.

\section{Discussion}

There is a paucity in the literature of reported cases demonstrating patients diagnosed with SLE having an associated large vessel vasculitis. The classic large vessel vasculitides include giant cell arteritis and Takayasu's arteritis [1]. In one case report, there was an associated large vessel vasculopathy in a Japanese patient with a background diagnosis of SLE and temporal arteritis [7]. We found a similar case to ours where there was a patient with a Takayasu's arteritis presentation followed by an associated diagnosis of SLE [8]. In this reported case, the patient was a 24 year old Indian female who initially presented with clinical symptoms and signs consistent with a diagnosis of Takayasu's pulseless arteritis. Three years later she then represented with rash, arthralgia, non scarring alopecia and other clinical features of SLE [8]. In our case, the patient similarly presented originally with clinical features more consistent with a diagnosis of Takayasu's pulseless arteritis but with a much more persistently elevated ESR. In

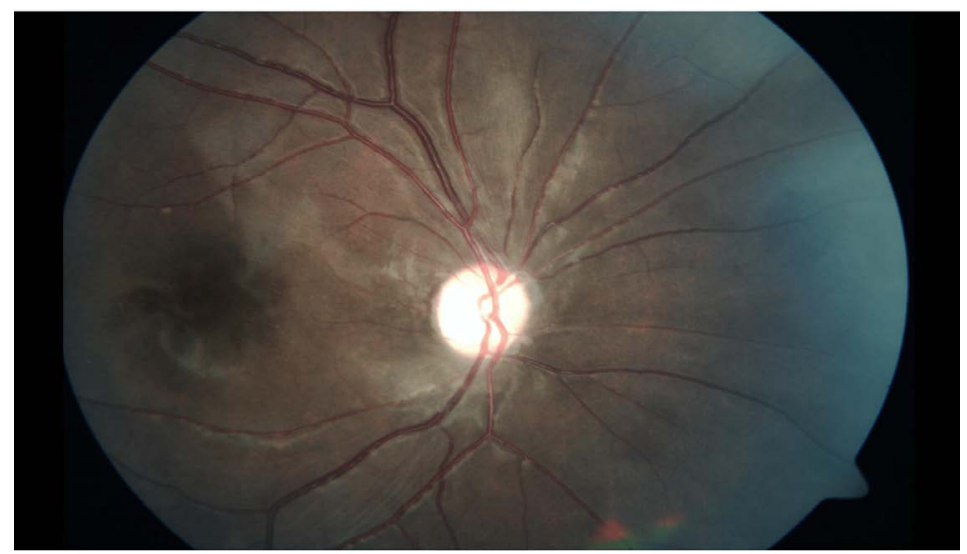

Figure 6. Retinal image demonstrating pale retinal background. 
our patient, the diagnosis of SLE was made on the same admission and based on the previous complaints of arthralgia plus the positive autoimmune blood investigations.

Of note, there have been reported cases of non specific aortitis involving the aorta and its main branches with non specific symptomatology unfulfilling the diagnostic criteria for SLE [9]. Aortoarteritis is more prevalent in Japan and Afro-asian countries and has been noted to rarely be associated with SLE [10].

Another differential diagnosis worthy of mention includes a study by Wichremasinghe et al. [11]. They reported a small number of patients with emboligenic aortoarteritis where thrombi formation occurred from a transient form of focal aortoarteritis involving the medial elastic tissue of the aorta. This led to a potential etiology for an ischemic stroke in the younger population. None of their patients had a diagnosis of SLE. It is plausible that our patient could have had thromboembolism from inflammatory disease of the aorta and one of its main branches giving rise to the middle cerebral occlusion and possibly the right ophthalmic artery as well.

The boy presented with what appeared to be a good fit for the diagnosis of Takayasu's pulseless arteritis. The absent pulses, involvement of the aorta and great vessels and raised ESR were well in keeping with this diagnosis [12]. However, Takayasu's pulseless arteritis is seen primarily in Asian women and is not associated with lupus antibodies [8] [13]. Furthermore, there have not been any reported cases of Takayasu's pulseless arteritis in the Caribbean population plus SLE is a relatively common disorder in people of Afro-Caribbean descent [14] [15]. Our patient met the criteria for the diagnosis of SLE based on the EULAR/ ACR scoring scale [16].

\section{Conclusion}

Even though the occurrence of SLE associated with a large vessel vasculitis is an unusual occurrence in the medical literature, the incidence is important to note as it can impact on the outcome of patients' morbidity and mortality.

\section{Conflicts of Interest}

The authors declare no conflicts of interest regarding the publication of this paper.

\section{References}

[1] Gulati, A. and Bagga, A. (2010) Large Vessel Vasculitis. Pediatric Nephrology, 25, 1037-1048. https://doi.org/10.1007/s00467-009-1312-9

[2] Irlapati, R.V.P., Sabella, A.R. and Rajasekhar, L. (2016) AB0503 Large Vessel Vasculitis in Systemic Lupus Erythematosus-A Case Series from a Single Centre in South India. Annals of the Rheumatic Diseases, 75, 1077-1078. https://doi.org/10.1136/annrheumdis-2016-eular.2642

[3] Ioannidis, S., Mavridis, M. and Mitsias, P.D. (2018) Ischemic Stroke as Initial Manifestation of Systemic Lupus Erythematosus: A Case Report and Review of the Li- 
terature. eNeurologicalSci, 13, 26-30. https://doi.org/10.1016/j.ensci.2018.11.001

[4] Tsze, D.S. and Valente, J.H. (2011) Pediatric Stroke: A Review. Emergency Medicine International, 2011, Article ID: 734506. https://doi.org/10.1155/2011/734506

[5] Albers, G.W., Amarenco, P., Babikian, V.L., Biller, J., et al. (1997) Etiology of Stroke. Stroke, 28, 1501-1506. https://doi.org/10.1161/01.STR.28.7.1501

[6] Aljanabi, N.M., Mamtani, S.S., Acharya, A., Gupta Rauniyar, R.P. and Malik, B.H. (2019) Association between Cerebrovascular Accident and Vasculitis: Myth or Reality? Cureus, 11, e6345. https://doi.org/10.7759/cureus.6345

[7] Waki, D., Onishi, A. and Morinobu, A. (2019) Large Vessel Vasculopathy in a Patient with Systemic Lupus Erythematosus: A Case Report. Journal of Medical Case Reports, 13, Article No. 189. https://doi.org/10.1186/s13256-019-2126-4

[8] Bandyopadhyay, D., Ganesan, V., Bhar, D., Bhowmick, D., Sasmal, S., Choudhury, C., et al. (2015) Takayasu's Arteritis with Systemic Lupus Erythematosus: A Rare Association. Case Reports in Rheumatology, 2015, Article ID: 934196. https://doi.org/10.1155/2015/934196

[9] Thenabadu, P.N., Rajasuriya, K. and Wickremasinghe, H.R. (1970) Non-Specific Arteritis of the Aorta and Its Main Branches. British Heart Journal, 32, 181-188. https://doi.org/10.1136/hrt.32.2.181

[10] Chakrabarti, N. and Chattopadhyay, C. (2012) Aortoarteritis with Systemic Lupus Erythematosus and Secondary Antiphopholipid Syndrome. Indian Dermatology Online Journal, 3, 66-68. https://doi.org/10.4103/2229-5178.93483

[11] Wickremasinghe, H.R., Peiris, J.B., Thenabadu, P.N. and Sheriffdeen, A.H. (1978) Transient Emboligenic Aortoarteritis Noteworthy New Entity in Young Stroke Patients. Archives of Neurology, 35, 416-422. https://doi.org/10.1001/archneur.1978.00500310018004

[12] Johnston, S.L., Lock, R.J. and Gompels, M.M. (2002) Takayasu Arteritis: A Review. Journal of Clinical Pathology, 55, 481-486. https://doi.org/10.1136/jcp.55.7.481

[13] Numano, F. (2002) The Story of Takayasu Arteritis. Rheumatology, 41, 103-106. https://doi.org/10.1093/rheumatology/41.1.103

[14] Flower, C., Hennis, A.J.M., Hambleton, I.R., Nicholson, G.D., Liang, M.H. and Barbados National Lupus Registry Group (2012) Systemic Lupus Erythematosus in an African Caribbean Population: Incidence, Clinical Manifestations, and Survival in the Barbados National Lupus Registry. Arthritis Care \& Research, 64, 1151-1158. https://doi.org/10.1002/acr.21656

[15] Cabas-Vargas, J., Patel, N.M., Cohen, J. and Ginzler, E.M. (2012) Sociodemographic Characteristics of SLE Patients in a Large Metropolitan Area with a High Afro-Caribbean Population. Arthritis Research \& Therapy, 14, A49. https://doi.org/10.1186/ar3983

[16] Aringer, M., Costenbader, K., Daikh, D., Brinks, R., Mosca, M., Ramsey-Goldman, R., et al. (2019) European League against Rheumatism/American College of Rheumatology Classification Criteria for Systemic Lupus Erythematosus. Arthritis \& Rheumatology, 71, 1400-1412. 


\section{Abbreviations}

SLE: Systemic lupus erythematosus

ESR: Erythrocyte sedimentation rate 